\title{
Oral health status of disabled children
}

\author{
Sultana Gul Nahar ${ }^{1}$, Md. Amzad Hossain ${ }^{1}$, Mohammod Borhan Uddin Howlader ${ }^{1}$, Anam Ahmed ${ }^{2}$ \\ ${ }^{1}$ Department of Prosthodontics, Dhaka Dental College, ${ }^{2}$ Department of Oral \& Maxillofacial Surgery, \\ University Dental College.
}

\begin{abstract}
110 disabled and 110 normal healthy children with the age range from 3 to 14 were examined in this cross sectional study. The average number of decayed tooth found 5.6 in deciduous and 6.5 in mixed dentition in disabled children, and the numbers were 3.5 and 4.0 respectively in normal children. Average number of missing tooth was 1.3 in disabled and was 1.0 normal child. The oral hygiene index value was 3 in disabled and 2.47 were in healthy children. In the disabled children, $36 \%$ respondents had normal gingiva, $50 \%$ had mild gingivitis and $14 \%$ had marked gingivitis; but in the normal children, about $73 \%$ showed normal gingiva, 23\% developed mild gingivitis and only $4.5 \%$ had marked gingivitis.
\end{abstract}

\section{Introduction}

The term disability refers to any impairment that restricts or limits daily activity in some manner. ${ }^{1}$ There are disparities in oral health of children with disabilities and other special health care needs ${ }^{2}$ Clinical account and emerging data attest the increase risks of oral disease in children with $\operatorname{disability~}^{3,4}$.

Dental caries is the most unmet health care among all children $^{5}$ including disabled ones ${ }^{6}$. A comparative assessment of the state of dentition and oral hygiene between disabled and healthy young people of same age ${ }^{7}$ revealed that the frequency of dental caries in both groups was $100 \%$. The average DMF was 11.96 in disabled group and 6.58 in the healthy group. The largest number of teeth with active caries per person was 8.21 in disabled children whereas the number was 2.27 in healthy ones. Dental caries treatment index (DTI) was 0.24 in disabled group and 0.59 in the healthy group. Oral hygiene index (OHI) in disabled group was 1.78 and in healthy group was 0.34 ; the index $(\mathrm{OHI})$ was 0.29 in girls and 0.38 in boys.

In Bangladesh, Kalam and Aziza ${ }^{8}$ found $82-95 \%$ periodontal problem and 1.7 DMF value in 12-19 year old normal children but no national database exists to document oral health status of children with disabilities or special care needs-not even any study was carried out on dental management of disabled children in the country. But it can be assumed that the situation is not better than that of the other countries of the world because a wide segment of the population is affected by disability in Bangladesh. There are some health promotion activities or facilities for disabled people in some centre in Bangladesh but there is no dental care delivery system for this group of people. This present study was carried out to find out the oral health status of the disabled children in terms of some indices: decayed, missing, filled teeth index (DMFT), oral hygiene index (OHI), and gingival index $(\mathrm{GI})^{9-11}$.

\section{Material and Methods}

This cross sectional comparative type of study was carried out in a disabled center and in an elementary school at Malibag area of Dhaka City. A structured questionnaire was developed to find out the oral health status indices: DMFT, OHI, and $\mathrm{GI}^{9-11}$. 110 disabled and 110 normal healthy children were selected and they are referred as Group I and Group II respectively for the convenience of the study. Every student and his/her guardian was interviewed and examined clinically using dental mirror and probe under sufficient examination light to see clinically the oral hygiene status in terms of DMF, OHI, and $\mathrm{GI}^{9-11}$. The status was recorded for both in deciduous and mixed dentitions. The Collected data were compiled and finally edited on a master chart for computer analysis with the help of software program SPSS (statistical package for social science). 


\section{Results}

Among 220 children 110 were disabled and 110 were normal children in this study. Oral health status was recorded in terms of DMF, OHI, and GI.

Table I: DMFT status of the children

\begin{tabular}{|c|c|c|c|c|}
\hline \multirow[t]{2}{*}{ DMFT } & \multicolumn{2}{|c|}{ Group I ( $\mathrm{n}=110)$} & \multicolumn{2}{|c|}{ Group II (n=110) } \\
\hline & $\begin{array}{c}\text { Deciduous/ } \\
\mathrm{dft}\end{array}$ & $\begin{array}{c}\text { Mixed/ } \\
\text { dmft }\end{array}$ & $\begin{array}{c}\text { Deciduous/ } \\
\mathrm{dft}\end{array}$ & Mixed/dmft \\
\hline $\mathrm{d}$ & 5.6 & 6.5 & 3.9 & 4.0 \\
\hline $\mathrm{m}$ & 0.0 & 1.3 & 0.0 & 1.0 \\
\hline f & 0.0 & 0.0 & 2.0 & 2.1 \\
\hline $\begin{array}{c}\text { Total } \\
\text { (dmft) }\end{array}$ & 5.6 & 7.8 & 5.9 & 7.1 \\
\hline
\end{tabular}

Group I: Disabled children (study group), Group II: Normal healthy children (control group).

Mixed Dentition: Deciduous (milk) and Permanent teeth are present in the Mouth.
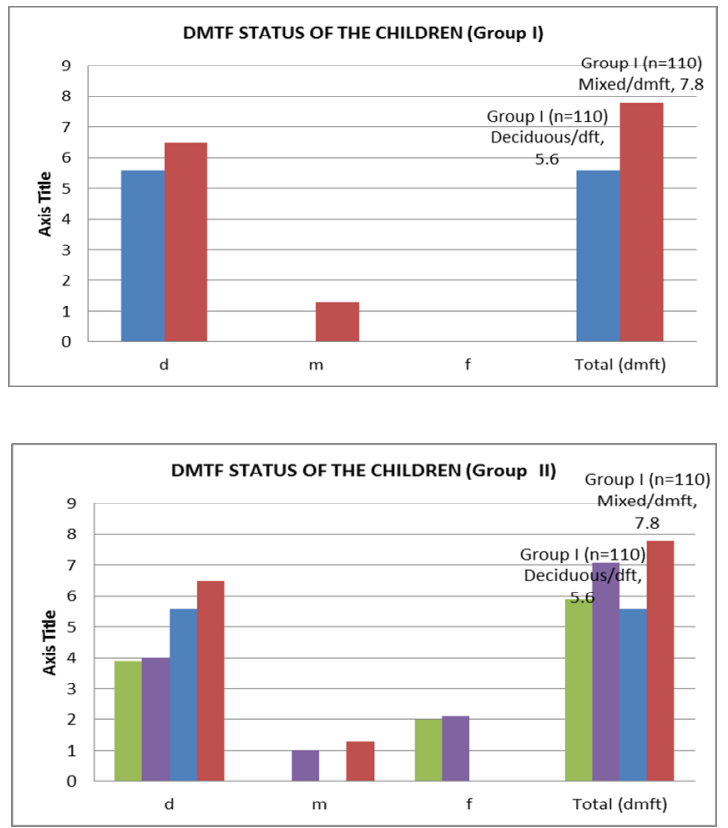

Table I showed that $\lambda^{2}=0.05, \mathrm{P}$-value $=0.82$. This data is not statistically significant. But number of decayed tooth in both deciduous and mixed dentition is more in disabled than normal children.

Decayed, Missing and Filled teeth are recorded in 110 disabled and 110 normal healthy children (Table-1). Average number of decayed tooth was 5.6 in deciduous and 6.5 was in mixed dentition in disabled children, whereas the numbers were 3.5 and 4.0 respectively in normal children. No missing tooth in deciduous dentition found in either group but the numbers were 1.3 and 1.0 in mixed dentition of both groups. No filled teeth found in disabled group, but the value was 2.0 in deciduous and 2.1 was in mixed dentition of healthy children.
Table II: Oral hygiene status of the respondents.

\begin{tabular}{lcccc}
\hline Respondent & Average DI & Average CI & OHI (DI+CI) & OHI \\
\hline Group I & 2.33 & .67 & $2.33+.67$ & 3 \\
Group II & 1.97 & .5 & $1.97+.5$ & 2.47 \\
\hline
\end{tabular}

Group I: Disabled children (study group), Group II: Normal healthy children (control group).

Table II showed that $\lambda^{2}=0.15, \mathrm{P}$-value $=0.98$. This data is not statistically significant. But average DI, CI was higher in case of disabled than normal children.

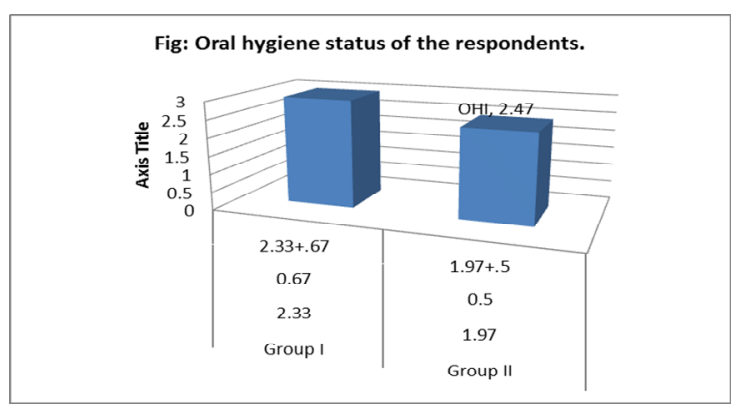

OHI: Oral Hygiene Index, DI: Debris Index, CI: Calculus Index The oral hygiene status of the children of this study (Table-2) was 3 in disabled group and the value was 2.47 in normal group.

Table III: Gingival status of the children.

\begin{tabular}{lcccc}
\hline GI & \multicolumn{2}{c}{ Group I $(\mathrm{n}=110)$} & \multicolumn{2}{c}{ Group II $(\mathrm{n}=110)$} \\
& Number & Percentage & Number & Percentage \\
\hline 0 & 40 & 36.36 & 80 & 72.73 \\
1 & 55 & 50.00 & 25 & 22.77 \\
2 & 15 & 13.64 & 05 & 4.50 \\
\hline Total & 110 & 100 & 110 & 100 \\
\hline
\end{tabular}

GI: Gingival Index ( $0=$ normal, $1=$ mild gingivitis, $2=$ gingivitis $)$
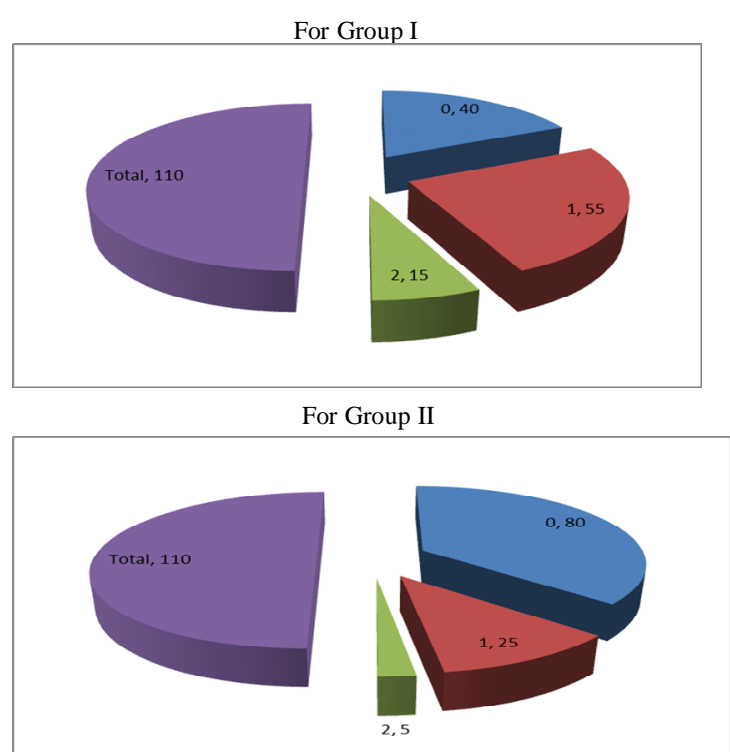

Table III showed that $\lambda^{2}=29.58, \mathrm{P}$-value $=0.000$. This data is strongly statistically significant. $(\mathrm{P}<0.05)$. 
The gingival status of the children was also recorded (Table-III). In disabled children, about $36 \%$ respondents had normal gingivae, $50 \%$ had mild gingivitis and about $14 \%$ had severe gingivitis.

In the healthy group, about $73 \%$ respondents were normal in terms of gingivitis, about $23 \%$ had mild gingivitis and only $4.5 \%$ had severe gingivitis was found in this group.

\section{Discussion}

The average number of decayed, filled and missing teeth found in the children of this study are not exactly similar to the value observed by studies ${ }^{4,5}$ because of limitation of recording facilities available in the schools where the study was carried out. The oral hygiene status observed in this study is more or less similar to others studies ${ }^{6,7}$. It attests that parents of the children are well aware about the oral hygiene of their children and accordingly they instruct and let them to follow the hygiene measures necessary. Gingival index recorded in this study recommends that more oral heal programs are needed in disabled school children to address and prevent the juvenile gingivitis which causes periodontitis and loosening of teeth. The status observed in this study is also poor in comparison to other studies $^{4-6}$.

\section{Acknowledgement}

The authors would like to acknowledge the parents, guardians and teachers of the children of this study. They would also like to acknowledge the school authority and management for giving the permission to carry out this study.

\section{References}

1. National Institute on Disability and Rehabilitation Research. Disability Statistics. Rehab Brief 1993; $14: 1-4$.

2. The Federal Maternal Child Health Bureau: Children and adolescents are special health care needsdefinition.

3. Nowak AJ, ED. The Handbook. 2nd ed. Chicago: American Academy of Pediatric Dentistry; 1999.

4. Leiter V, Krauss M, Anderson B. Oral health care for children with special health care needs: Findings from the family partner project. Abstract presented as The Face of a Child: surgeon General's Conference on children and oral health, Jun 12-13, 2000, Washington DC.

5. Newacheck PW, Hughes DC, Hung YY, Wong S, Stoddrd JJ. The unmet health needs of America's children. Pediatrics 2000; 105(4 pt 2):989-997

6. Necheck P, McManus M, Fox HB, Hung Y, Halfon N. Access to health care for children with special health care needs. Pediatrics 2000; 105:760-766.

7. Stachurski P, Warsz M, Rudnicka-Siwek K, Zioło A. Assessment of the state of dentition and oral hygiene in 16-25-year-old young people with mild and moderate mental disability. Advances in Medical Sciences 2006; Vol. 51: Suppl.1.

8. MA Kalam Joarder and Aziza Begum. Prevalence and severity of periodontal disease and dental caries in Bangladesh. International Dental Journal 1996; 46: 7681 .

9. Collins, W.J.N., et al. A Handbook for Dental Hygienists. 4th ed. Woburn, MA: John Wright, 1999.

10. Wilkins, Esther M. Clinical Practice of the Dental Hygienist. 7th ed. Philadelphia: Williams and Wilkins, 1994.

11. "Oral Health Methods and Indices." WHO Oral Health Country/Area Profile Programme, 1997. 